\title{
Screening for psychological distress in patients with lung cancer: results of a clinical audit evaluating the use of the patient Distress Thermometer
}

\author{
Johanna Lynch • Frances Goodhart • \\ Yolande Saunders • Stephen J. O'Connor
}

Received: 24 September 2009 / Accepted: 7 December 2009 / Published online: 13 January 2010

(C) The Author(s) 2010. This article is published with open access at Springerlink.com

\begin{abstract}
Purpose Patients with lung cancer frequently suffer psychological distress and guidelines in the United Kingdom recommend screening of all cancer patients for this problem. The audit investigated use of the Distress Thermometer in terms of staff adherence to locally developed guidelines, patient willingness to use the tool, its impact on referral rates to clinical psychology services and concordance between the tool and the clinical assessment. Method Use of the Distress Thermometer was audited over a 3-month period in one lung cancer outpatient clinic. Referrals to clinical psychology services in response to clearly delineated referral indicators were assessed. Patientreported outcomes were compared with practitioner assessment of need during clinical consultations to see whether the tool was measuring distress effectively.

Results Thirty three of 34 patients used the Distress Thermometer during the audit period. Ten reported distress levels above 4 in the emotional or family problems
\end{abstract}

\footnotetext{
J. Lynch $(\bowtie) \cdot$ F. Goodhart $\cdot$ Y. Saunders

The Hillingdon Hospital,

Pield Heath Road,

Uxbridge UB8 3NN, UK

e-mail: johanna.lynch@thh.nhs.uk

F. Goodhart

e-mail: frances.goodhart@thh.nhs.uk

Y. Saunders

e-mail: yolande.saunders@thh.nhs.uk

\section{S. J. O'Connor}

Department of Health Care and Nursing Science,

Faculty of Health, Medicine and Life Sciences,

Maastricht University,

Universiteitssingel 40, Postbus 616,

6200 MD Maastricht, The Netherlands

e-mail: s.oconnor@zw.unimaas.nl
}

domains. On ten occasions, the clinical interview identified problems not elicited by the Distress Thermometer. Guidelines were adhered to by staff, and patients were offered information about local support services and referral to clinical psychology services where indicated. Whilst all patients were happy to receive written information about further sources of support, none wanted to be referred to psychological services at that time.

Conclusions The Distress Thermometer is acceptable to patients with lung cancer in outpatient settings but it did not increase referrals for psychological support. Staff found it to be a useful tool in opening up communication about patient issues although it should not replace a comprehensive clinical interview.

Keywords Lung cancer. Psychological screening . Distress Thermometer . Clinical audit

\section{Introduction}

Guidelines from the United Kingdom's National Institute of Clinical Excellence (NICE) suggest that all cancer patients should undergo regular screening for signs of psychological distress [36]. Despite these recommendations, the impact of regular psychological screening remains largely untested in the UK. Questions remain about its value since it is not known whether the use of screening tools will significantly improve the identification of those requiring specialist assessment or interventions for distress, relative to other forms of assessment, such as the clinical interview [27]. It is not known whether screening for signs of psychological distress and subsequent referral to specialist psychological services will result in significantly improved health outcomes in comparison to the routine care provided to cancer 
patients. Concerns have also been raised that screening may lead to many 'false positive' results which are likely to overwhelm the limited resources of a hospital's psychological services team [18].

It has been suggested that formal screening is necessary because health care professionals might not always recognise signs of psychological distress in their patients [15, 20], care tending to focus upon physical aspects of the illness rather than psychological issues, especially in busy oncology clinics where interventions focus on cancer treatments and their side effects [31]. Psychosocial problems such as distress may be regarded as 'normal' sequelae to having cancer [30], leading healthcare professionals to minimise or ignore these concerns as part of their own egodefensive function [38]. Staff could lack confidence in managing overt signs of distress and subsequently fail to explore these concerns more fully [32]. Professionals might avoid delving into patients' emotional states for fear of wasting precious time and resources [15].

Patient-specific factors could further contribute to this problem since the diagnosis of anxiety, depression, or generalised distress might be confounded by malignancy or its treatment. Loss of appetite, fatigue, insomnia due to unalleviated pain, or the effects of chemotherapy or radiotherapy could just as easily suggest the presence of depression [32]. Patients may be reluctant to discuss their concerns with staff they perceive to be too busy, not wanting to be seen as demanding or difficult [40]. Embarrassment or the stigma associated with psychological weakness or mental illness could prevent them from seeking help [24].

\section{The Distress Thermometer}

A rigidly structured diagnostic interview based upon the Diagnostic and Statistical Manual of Mental Disorders [13] has traditionally been viewed as the gold standard for the diagnosis of psychological problems [45]. This is impractical in every case given patient volumes in most outpatient clinics [23], and the emphasis on the management of biophysiological problems in most cancer settings [31]. One possible solution to this problem is the use of brief screening tools aimed at identifying those patients experiencing severe forms of distress and referring them for further assessment by mental health professionals.

The National Comprehensive Cancer Network [34] suggest that the Distress Thermometer is ideally suited for use by nurses working in cancer settings because it assesses a broad range of problems associated with elevated distress levels. Focusing on the self-reported problems identified on the Distress Thermometer is regarded as a good starting point for further discussion in the clinical interview. The word 'distress' carries less stigma for most people than anxiety or depression which may pathologise many normal responses to being diagnosed with cancer [30]. Distress is defined as:

'An unpleasant experience of an emotional, psychological, social or spiritual nature, that interferes with the ability to cope with cancer treatment, which extends along a continuum from common normal feelings of vulnerability, sadness and fear, to problems that are disabling such as true depression, anxiety, panic and feeling isolated or in a spiritual crisis' [24]

The Distress Thermometer is a modified visual analogue scale that resembles a thermometer. It ranges from 0 (no distress) to 10 (extreme distress; Fig. 1). It also contains an accompanying list of 34 problems grouped into five categories (practical, family, emotional, spiritual/religious and physical). Respondents are instructed to indicate whether any of the items listed has been a problem in the past week by selecting from a fixed yes/no response, allowing an overview of the issues affecting a patient's level of distress [30]. Healthcare professionals can then help patients to cope with these concerns by focusing on specific elements giving rise to distress which might be modifiable with interventions such as better pain relief, financial counselling or assistance with activities of daily living [43]. The Distress Thermometer shown has been slightly adapted for local use to aid comprehension. The original tool shows the thermometer in black and white. We added colours ranging from green at the lower end of the scale representing little or no distress through yellow/ orange indicating moderate distress to red at the top, signifying higher distress levels.

The assessment tool is easily completed within 5 minutes [16]. Using a visual analogue scale in the form of a thermometer which is familiar to patients [40] may reassure them that healthcare professionals are interested in all aspects of the disease experience and its treatment [25]. Various studies have tested the validity of the Distress Thermometer against other validated tools such as the Hospital Anxiety and Depression (HADS) Scale [1, 17, 27, $40,42]$. Its use has been validated in UK cancer populations by Gessler et al. [16] who demonstrated that it was acceptable to $95 \%$ of 171 participants. These authors suggested that a 'traffic light system' be used in response to scores obtained, 0-4 obtaining a green light and care as usual, 5-6 (yellow) indicating that closer monitoring was required and 7 or more (red) alerting clinicians to discuss the issue of distress with their patient and refer for specialist interventions where appropriate.

A score of 4 on the Distress Thermometer was found to be a reasonable cut-off value for identifying distressed 


\begin{tabular}{|c|c|c|}
\hline $\begin{array}{l}\text { First please circle the number }(0-10) \text { that best } \\
\text { describes how much distress you have been } \\
\text { experiencing in the past week including today. }\end{array}$ & \multicolumn{2}{|c|}{$\begin{array}{l}\text { Second, please indicate if any of the following has been a problem for you in the } \\
\text { past week including today. Be sure to check YES or NO for each. }\end{array}$} \\
\hline Extreme Distress & 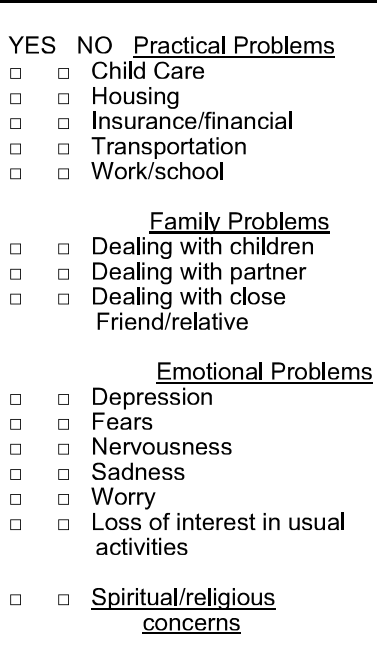 & 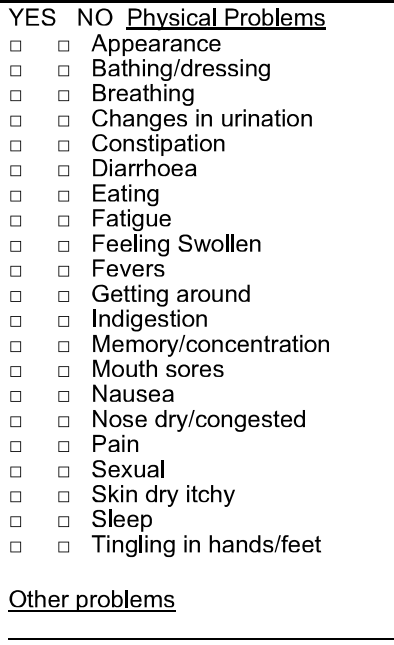 \\
\hline
\end{tabular}

Fig. 1 Patient Distress Thermometer and problem list

patients and referring them for psychological consultation $[2,27]$. One study [23] found that the tool's sensitivity and specificity varied according to the cut-off value used however, others suggest that a score higher than 4 indicated general psychosocial morbidity whilst 5 or more indicated severe distress [17]. The lower the cut-off value used, the higher the risk of over-identifying distressed individuals, whereas higher cut-off values carry the risk of missing truly distressed individuals.

\section{Methodology}

Patients with lung cancer are especially prone to psychological distress $[9,14,15,44]$ which may be accentuated by guilt or self-blame for smoking [9]. They often have a poor prognosis in comparison to other patient populations, and those with distress should be identified as quickly as possible [36]. The Distress Thermometer was introduced into a lung cancer follow-up clinic in a District General Hospital in London. Patients attending this clinic have completed their primary treatment for lung cancer. Patients were approached by staff and asked if they would like to complete the Distress Thermometer. The impact of the implementation was evaluated by a clinical audit 6 months after its introduction. Clinical audit is a quality improvement process which seeks to systematically review patient care against explicit criteria [35]. Within this context, quality improvement typically involves implementing a specific change in practice and evaluating its effect at a predetermined point in the future $[7,22]$. Concerns about the consistency of its implementation and use on a daily basis suggested that the audit cycle [29] should provide the framework for the clinical audit.

The aims of the audit were:

- To collect information on patient willingness to use the Distress Thermometer and to elicit reasons for refusal to use the tool

- To collect data on reasons for non-adherence to the locally developed guidelines when distress was apparent in patients

- To assess the impact of the tool on referral rates to clinical psychology services

- To measure how often patients disclosed distressing concerns to the clinical nurse specialist (CNS) and consultant that they had not indicated on the Distress Thermometer

A data collection sheet was developed by the multiprofessional team working in the lung cancer clinic. It was piloted on four patients by a consultant and a palliative care CNS not involved in its original development in order to provide an objective perspective on its clarity. During the pilot period, it was noted that patients asked questions about disease status during consultations, but it was difficult to ascertain if distress was driving such questioning. The consistency of observations was assessed by comparing individual coding decisions and discussing any 
incidences where the consultant and the CNS came to different conclusions about the patient's distress state in order to reduce the possibility of observer bias [6]. The pilot reviewers reported that the tool was easy to understand and complete, but that one disease category (mesothelioma) had been omitted. This was subsequently added to the final data extraction sheet.

Data were entered onto the data collection sheet (Fig. 2) from medical and nursing notes, some observation, and direct questioning of staff and patients in the clinic [26]. Patient performance status was determined and recorded using the Eastern Co-operative Oncology Group (ECOG) Performance Rating Scale. The patient's home circumstances and the extent of their social support network were recorded [4]. Uptake of other services such as community nurses, social services or hospices/respite care was also recorded by questioning the patient and family.

The first question on the audit sheet asked if the patient had completed the Distress Thermometer. Reasons for non-completion of the Distress Thermometer were explored using free text, and prompts such as 'patient too tired', 'patient confused' etc. [9, 21]. Adherence with local guidelines (Fig. 3) was documented using tick boxes. Issues arising during the consultation which were not identified by the Distress Thermometer were entered onto the data sheet. The CNS and doctor saw patients together within the clinic, but completed the audit sheet separately. These independent observations were then compared to ascertain whether these problems had been identified by Distress Thermometer. The aim was to see whether both the CNS and consultant identified these as missing from the Distress Thermometer and to reduce the risk of selectivity in note taking [41].

\section{Results}

Audit data were collected prospectively over a three month period. All data were anonymised for audit purposes.

\section{Demographic factors}

During the audit period, 34 patients with lung cancer attended the clinic, $44 \%$ of whom were male $(n=15)$ and $56 \%$ female $(n=19)$. Thirty-three patients completed the tool. One was unable to complete it herself, but felt that staff were too busy to assist her in its completion. Twentyseven patients $(79 \%)$ lived within wards of the borough with higher levels of deprivation and were $>65$ years of age. The majority (24) had advanced non-small-cell lung cancer whilst seven had mesothelioma. Time since initial diagnosis varied from less than 3 months to over 2 years, but 14 patients $(40 \%)$ had been diagnosed between
1-2 years. Most had received treatment, usually palliative radiotherapy (21). The majority (31) had functional impairment restricting their ability to carry out self-care or work as measured by the ECOG Performance Rating Scale (Table 1). Services used by patients included the support of the lung cancer CNS $(n=34)$, district nurse 17 (50\%) and Community Macmillan CNS 9 (26\%). Twenty one received care from their partner, the rest were cared for by other close family members such as a daughter or granddaughter.

Global distress scores and problems most frequently identified

Patients were asked to indicate how distressed they had generally felt in the previous week. Figure 4 shows that of the 33 completed Distress Thermometers, 18 (55\%) scored themselves as being below 4, the cut-off point for further discussion or referral.

Patients were then asked to indicate which of the 34 problems listed on the Distress Thermometer were of concern and which were the most difficult giving each problem an individual score out of 10 . The most frequently identified problems were of a physical nature such as breathing, eating, pain, fatigue and sleep, reflecting symptom prevalence studies in patients with lung cancer [10, 11]. Individual rating for identified symptoms scored between 2 and 10 (Table 2).

Emotional concerns and adherence with local guidelines

Nineteen patients $(58 \%)$ ticked problems in the emotional category on the Distress Thermometer problem list. Of these, seven (four male and three female) identified problems but did not give them a distress rating. All of these patients ticked multiple physical problems, each with high distress score ratings. Referral to the psychologist for further assessment was not indicated according to the guidelines, so interventions focused on dealing with these symptoms, although patients were also provided with information about local sources of practical and emotional support.

Figure 5 shows the scoring on the Distress Thermometer for emotional and family concerns of the 12 patients who gave these problems a rating. Two patients (females) ticked items under the emotional category on the Distress Thermometer checklist with scores below 4 . They were not offered referral to the psychologist as recommended in the guidelines, but were provided with information on local sources of support. Ten patients (seven female and three male) ranked items under the emotional or family problems category above the referral point of 4 (range 4-10), indicating that they 
Audit Data Extraction Sheet

Date data collected

Patient completed Distress Thermometer?

Yes $\square$ No $\square$ If not why i.e. too ill, confused, too upset

DATE OF CANCER DIAGNOSIS

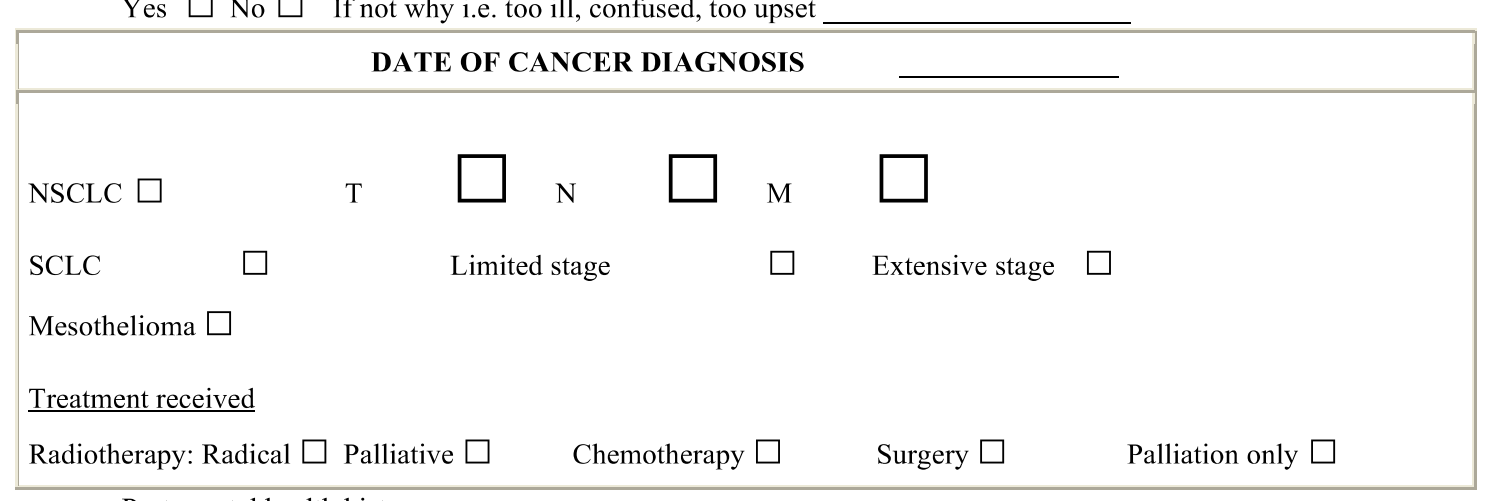

Past mental health history:

Co-morbidity:

\section{ECOG PERFORMANCE STATUS}

\begin{tabular}{|l|l|}
\hline Grade & \multicolumn{1}{|c|}{ ECOG } \\
\hline 0 & Fully active, able to carry on all pre-disease performance without restriction \\
\hline 1 & $\begin{array}{l}\text { Restricted in physically strenuous activity but ambulatory and able to carry out work of a light or sedentary } \\
\text { nature, e.g., light house work, office work }\end{array}$ \\
\hline 2 & $\begin{array}{l}\text { Ambulatory and capable of all self-care but unable to carry out any work activities. Up and about more than } \\
50 \% \text { of waking hours }\end{array}$ \\
\hline 3 & Capable of only limited self-care, confined to bed or chair more than 50\% of waking hours \\
\hline 4 & Completely disabled. Cannot carry on any self-care. Totally confined to bed or chair \\
\hline
\end{tabular}

\begin{tabular}{|c|c|}
\hline CURRENT SUPPORT SERVICES \\
\hline Lung CNS $\square \quad$ District Nurses $\square$ Macmillan Nurses $\square$ Social services $\square$ Other \\
Lives alone $\square \quad$ Lives with family/friends $\square$ Who is the carer i.e. spouse/daughter \\
\hline
\end{tabular}

\section{ISSUES EXPLORED DURING AUDIT - NOT IDENTIFIED ON DISTRESS THERMOMETER}

Practical problems such as housing/financial

Family problems such as dealing with children/partner

Emotional problems: depression, fear, nervousness

sadness, worry, loss of interest in usual activities

Spiritual / religious concerns

Physical problems

Fig. 2 Audit data extraction sheet

should be offered a referral to the clinical psychologist for further assessment of need. All ten patients were offered referral, but declined intervention for a variety of reasons. Three attributed their loss of interest in usual activities to the physical limitations of the condition, and said they were trying to adapt to these. One patient said that they were always a worrier and were used to it. Another reported that they would not like to talk about their feelings, and a third was going abroad in the following week, so could not take up the 
Fig. 3 Local guidelines for the management of distress in patients with lung cancer

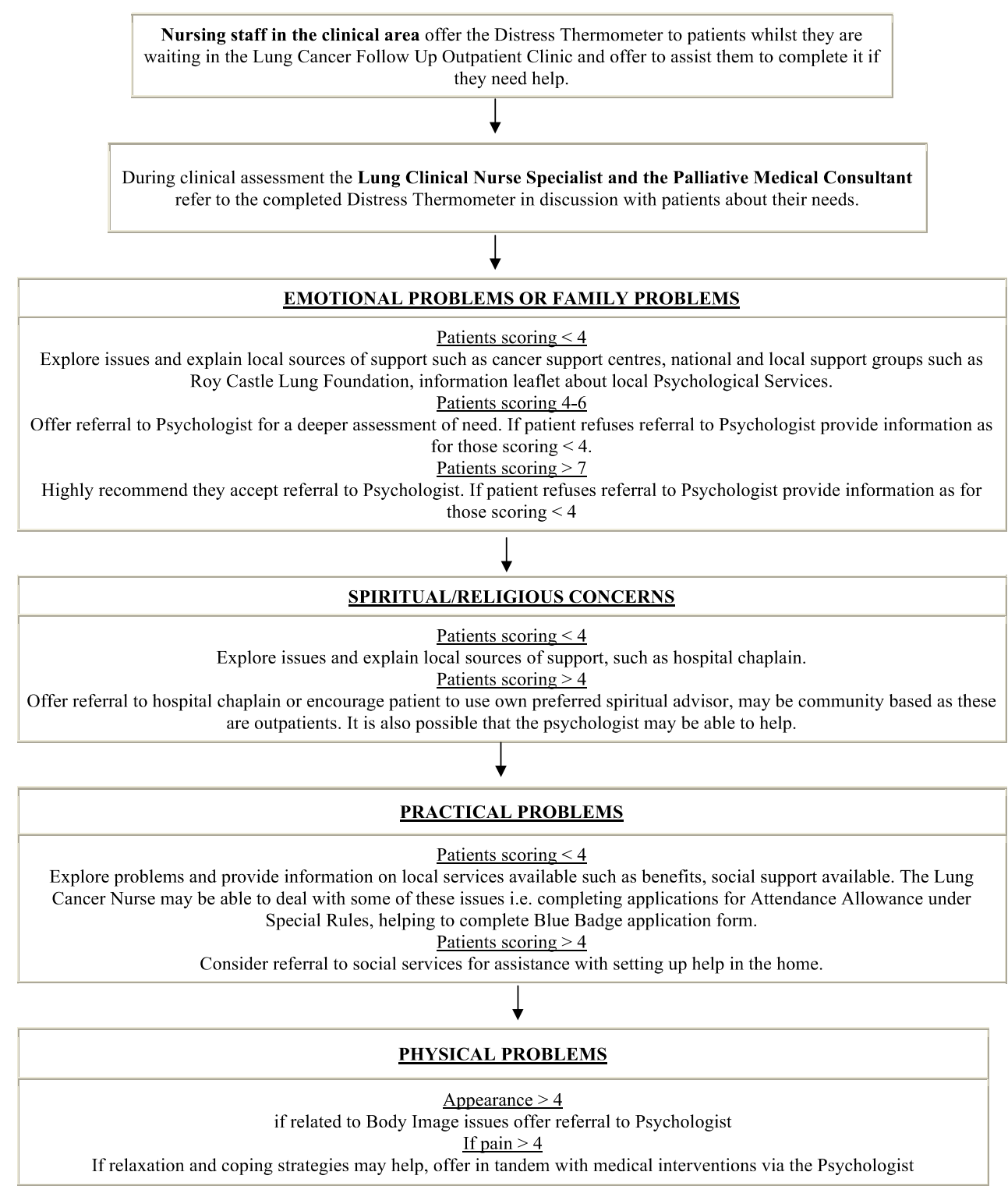

support offered. One patient said their loss of interest in usual activities was due to boredom and that they needed a holiday. Two recently bereaved patients said they were trying to come to terms with their loss with the help of friends and family, and another patient had completed counselling within the previous month and reported that they felt better for it. Figure 5 shows that all of these patients were provided with information about local sources of practical and emotional support in accordance with the local guidelines

Issues not identified by the Distress Thermometer

On ten occasions, patients discussed concerns of a physical (six), practical (two) or emotional (two) nature during consultations which they had not identified on the Distress Thermometer.

\section{Discussion}

Whilst early detection and intervention for psychosocial distress is recommended for patients with lung cancer [9], the results of this audit showed that use of the tool did not necessarily lead to increased referral for psychological support. Within this context, patients scoring above the cut-off did not wish to take up the offer of referral to clinical psychology for further assessment. Perhaps one reason why patients did not feel the need to accept further help was because the tool had allowed them to express their concerns sufficiently. One patient, for instance, felt we had adequately dealt with their worry after a conversation about questions related to their disease, whilst another left the clinic happier having addressed concerns about going away on holiday. When asked why they did not wish to take up referral to the psychology service, they indicated they had a 
Table 1 Demographic and disease related factors

\begin{tabular}{|c|c|c|}
\hline Variable & $n$ & $\%$ \\
\hline \multicolumn{3}{|l|}{ Age } \\
\hline$>56$ & 2 & \\
\hline $56-65$ & 5 & 15 \\
\hline $66-75$ & 13 & 38 \\
\hline $76-85$ & 14 & 41 \\
\hline \multicolumn{3}{|l|}{ Diagnosis } \\
\hline \multicolumn{3}{|l|}{ Non-small-cell lung cancer } \\
\hline Stage 1 & 1 & \\
\hline Stage 2 & 0 & \\
\hline Stage 3 & 15 & 44 \\
\hline Stage 4 & 8 & 24 \\
\hline Total NSCLC & 24 & 71 \\
\hline \multicolumn{3}{|l|}{ Small Cell Lung Cancer } \\
\hline Limited stage & 3 & \\
\hline Extensive stage & 0 & \\
\hline Total SCLC & 3 & 9 \\
\hline Mesothelioma & 7 & 20 \\
\hline \multicolumn{3}{|l|}{ Time since diagnosis } \\
\hline$<3$ months & 4 & 12 \\
\hline 3-6 months & 6 & 18 \\
\hline $6-12$ months & 3 & 9 \\
\hline $1-2$ years & 14 & 40 \\
\hline$>2$ years & 6 & 18 \\
\hline Not recorded & 1 & 3 \\
\hline \multicolumn{3}{|l|}{ Treatment received } \\
\hline Radical radiotherapy & 0 & 0 \\
\hline Surgery & 2 & 0 \\
\hline Chemotherapy only & 1 & 3 \\
\hline Chemotherapy and symptom control radiotherapy & 4 & 12 \\
\hline Palliative radiotherapy only & 21 & 61 \\
\hline Palliation only & 6 & 18 \\
\hline \multicolumn{3}{|l|}{ ECOG performance status } \\
\hline Stage 0 & 3 & 9 \\
\hline Stage 1 & 13 & 38 \\
\hline Stage 2 & 10 & 29 \\
\hline Stage 3 & 7 & 21 \\
\hline Stage 4 & 1 & 3 \\
\hline
\end{tabular}

good understanding of their distress and how best to manage it. For instance, a recognition that they wanted to manage a recent bereavement themselves, or that they had always been a worrier and had become used to it. This study indicates that the Distress Thermometer helps patients to discuss their feelings with their health care team, and recognise the coping skills they already have in place. They are willing to receive information about support services and can make their own decisions about whether to pursue these.

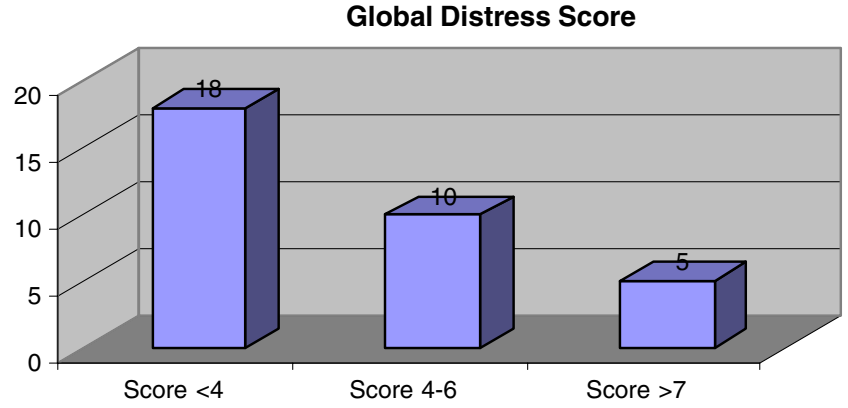

Fig. 4 Global distress scores

Another possible reason patients scoring above the cutoff point for referral were unwilling to see the clinical psychologist was because of poor specificity of the tool [23], the chosen cut-off point for referral, or both. Roth et al. [40] used a score of 5 as indicative of significant distress requiring referral to psychological services, but found that of the 29 patients referred for further evaluation by a psychiatrist; only eight met the Diagnostic and Statistical Manual of Mental Disorders [13] criteria for a psychiatric disorder. Gessler et al. [16] used a higher cut-off point of 7.

It may be that the tool did accurately detect distress levels and there were other reasons for patients' refusal of the interventions offered. The majority of our patients (94\%) were over 65 years of age, and the identification of psychological distress by screening in older adults may have little impact on subsequent treatment [28]. Referral rates of older patients to UK psychotherapy departments are generally low [33], and some may not want to be referred because of the stigma associated with 'mental health problems', fear of being labelled, or fear of being committed to institutional care [12]. According to Goffman [19], one coping strategy employed by a person wishing to avoid stigma is to reduce exposure. Some patients may have downplayed their true feelings in an effort to avoid exposure in spite of using the less stigmatising word 'distress' since this would still lead to referral to a psychologist.

Referral to a psychologist is still perceived to be stigmatising in some communities, particularly amongst the elderly, so it may be appropriate to consider different ways of introducing these services to patients which do not make direct reference to the term 'psychologist'. Studies in other fields such as breast cancer show that terms such as 'counsellor' or 'therapist' may be more acceptable to patients, and it may be wise to use these more neutral terms when patients are referred by the consultant or CNS for further psychological assessment. Even if psychological support was refused, the clinical psychologist was informed about those patients scoring above the cut-off point for referral and the score provided a 'red flag' for further screening and assessment at their next visit to the clinic. 
Table 2 Problems most frequently identified

\begin{tabular}{lcccc}
\hline Problem & Number of patients & Percentage & Mean score & Range \\
\hline Breathing & 21 & 64 & 6.7 & $2-10$ \\
Eating & 13 & 39 & 5.9 & $3-9$ \\
Pain & 12 & 36 & 5.6 & $2-8$ \\
Fatigue & 9 & 26 & 5.1 & $1-10$ \\
Sleep & 8 & 24 & 5.5 & $1-9$ \\
\hline
\end{tabular}

All of the patients scoring above the cut-off point for referral were from wards of the borough with higher levels of deprivation. People from lower socio-economic groups may find the emotional effects of cancer more difficult to cope with [8], but may not necessarily volunteer themselves for psychological therapies. A study by CancerBacup auditing uptake of their counselling service found that the majority of 384 clients booking an appointment were young females from non-manual social classes [5]. Other barriers to the uptake of psychological services in particular social groups include travel and other costs, or the cognitive and verbal abilities of clients [37]. The socially disadvantaged may also be more fatalistic, and exhibit learned helplessness or depression due to repeated exposure to situations over which they have little or no control [3,9].

Two patients raised emotional concerns during the consultation that they did not record on their completed Distress Thermometers. This may be because they were not willing to commit their feelings to paper but felt that

Scoring on Distress Thermometer

Emotional/Family Problems \& Adherance with Local Guidelines

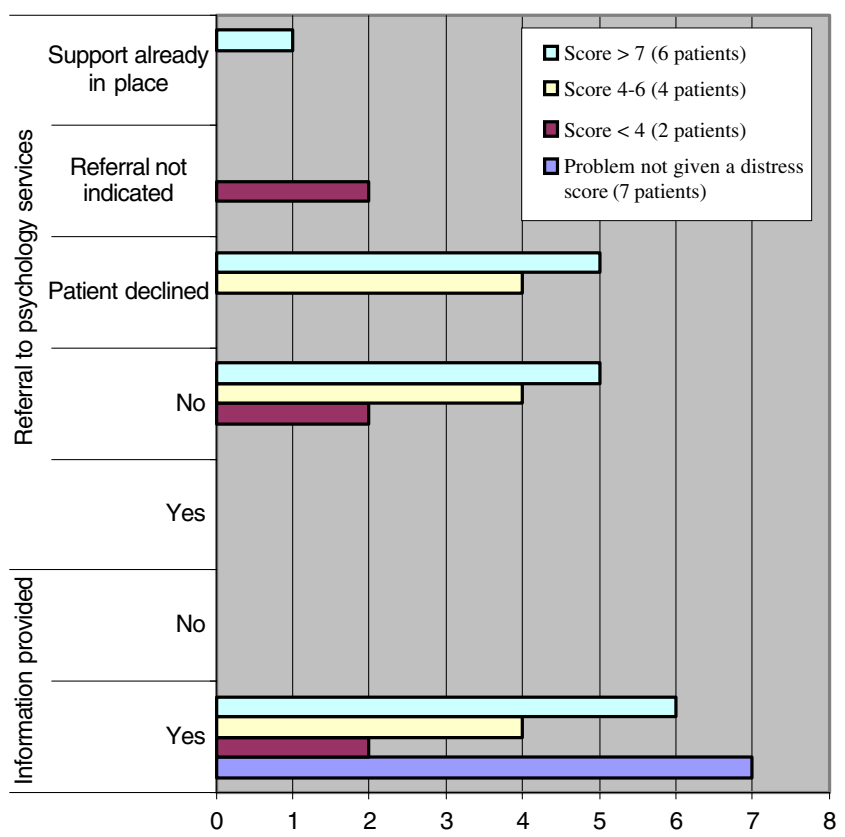

Fig. 5 Self-reported emotional and family problems and adherence to the local guidelines empathic discussion during the consultation enabled them to explore these concerns more fully [39]. These results raise concern, and indicate that a screening tool should not replace the clinical consultation where patients are given the opportunity to discuss their broader concerns with trained health care professionals.

In spite of initial reluctance, one patient did later acknowledge an increase in their distress level and requested referral for psychological support. This supports the conclusions of Gessler et al. [16] that the Distress Thermometer can enhance discussion between patients and professionals, and addresses important issues at an early stage, but that immediate referral for psychological assessment (particularly for those scoring just above the threshold) should be avoided.

One limitation of the work is that audit data were only collected once during the patient's illness trajectory, although NICE guidelines [36] recommend that psychological screening should be performed regularly. The audit was only designed to assess staff adherence and patient acceptability during a limited audit period however, and not to elicit time-series data which might constitute a separate worthwhile study. The audit sample is also modest in comparison to published research reports, making it difficult to draw statistically significant conclusions or generalisations from the data, although this was not the primary purpose of this institutional audit, and it should be noted that all but one patient passing through the clinic in the audit period agreed to take part.

Staff reflections on the use of the tool

Outpatient department staff stated that in spite of initial reservations, they would like to continue using the tool since it encouraged them to talk to patients about their concerns prior to their consultation with the doctor. The CNS found it useful as it opened the way for further discussions about the patient's psychological status, and for reflection on patients' progress using earlier scores. It also created a common coin of communication about the patient's concerns with other professionals such as GPs, community and Macmillan nurses. It was useful in alerting the team to potential problems which might need to be followed up at a later date. Staff found the tool useful 
because it brought up issues during consultations which might not normally have been discussed, enabling them to use consultation time more effectively by focusing on patient concerns. It also demonstrated to patients and their carers that the health care team were interested in all aspects of patient well-being.

\section{Conclusion}

Using the Distress Thermometer as a screening tool in the lung cancer clinic did not result in increased referrals to psychological support services. It was found to be acceptable to patients however, all but one of whom were able to complete it on their own or with help from outpatient staff. It was found to be a useful addition to the clinical assessment as it helped staff to open up discussions with patients about psychosocial concerns. For this reason, the Distress Thermometer continues to be used in the outpatient clinic, and a patient information booklet has been developed to provide further information to patients about the purpose of the screening tool, and the range of support services available to patients locally.

Open Access This article is distributed under the terms of the Creative Commons Attribution Noncommercial License which permits any noncommercial use, distribution, and reproduction in any medium, provided the original author(s) and source are credited.

\section{References}

1. Adams C, Clover K, Carter G (2005) Concurrent validity of the Distress Thermometer with other validated measures of psychological distress. Asia-Pacific Journal of Clinical Oncology 1 (Suppl):A15

2. Akizuki N, Akechi T, Nakanishi T, Elsho Y, Okamura M, Nakano T, Murakami Y, Uchitomi Y (2003) Development of a brief screening interview for adjustment disorders and major depression in patients with cancer. Cancer 97(10):2605-2613

3. Argyle M (1994) The psychology of social class. Routledge, London

4. Bloom JR (2000) The role of family support in cancer control. In: Braider L, Cooper CL, De-Nour A (eds) Cancer and the family. Wiley, Chichester, pp 49-75

5. Boudioni M, Mossman J, Boulton M, Ramirez A, Moynihan C, Leydon G (2000) An evaluation of a cancer counselling service. Eur J Cancer Care 9(4):212-220

6. Bowling A (2002) Research methods in health: Investigating health and health services. Open University Press, Maidenhead

7. Braine ME (2006) Clinical governance: applying theory to practice. Nursing Standard 20(20):56-65

8. Cardy P, Corner J, Evans J (2006) Worried sick: the emotional impact of cancer. [online] Available from: www.macmillan.org.uk (Accessed 24 October 2006)
9. Carlson LE, Angen M, Cullum J, Goodey E, Koopmans J, Lamont L, MacRae JH, Martin M, Pelletier G, Robinson J, Simpson JSA, Speca M, Tillotson L, Bultz BD (2004) High levels of untreated distress and fatigue in cancer patients. $\mathrm{Br} \mathrm{J}$ Cancer 90 (12):2297-2304

10. Claessens MT, Lynn J, Zhong A, Desbiens NA, Philips RS, Albert W, Harrell FE, Connors AF (2000) Dying with lung cancer or chronic obstructive pulmonary disease: Insights from SUPPORT. J Am Geriatr Soc 48(Suppl):146-153

11. Cooley ME, Short TH, Moriarty HJ (2003) Symptom prevalence, distress, and change over time in adults receiving treatment for lung cancer. Psycho-Oncology 12:694-708

12. Darby S, Marr J, Crump A, Scurfield M (1999) Older people, nursing and mental health. Butterworth Heinemann, Oxford

13. Diagnostic and Statistical Manual of Mental Disorders 4th Ed (DSM-IV-TR) (2000) Washington: American Psychiatric Association

14. Dugan W, McDonald M, Passik D, Rosenfield BD, Theobald D, Edgerton S (1998) Use of the Zung self-rating depression scale in cancer patients: feasibility as a screening tool. Psycho-oncology $7: 483-493$

15. Fallowfield L, Ratcliffe D, Jenkins V, Saul J (2001) Psychiatric morbidity and its recognition by doctors in patients with cancer. Br J Cancer 84(8):1011-1015

16. Gessler S, Low J, Daniells E, Williams R, Brough V, Tookman A, Jones C (2008) Screening for distress in cancer patients: is the Distress Thermometer a valid measure in the UK and does it measure change over time? A prospective validation study. Psychooncology 17(6):538-547

17. Gil F, Grassi L, Travado L, Tomamichel M, Gonzalez JR (2005) Use of distress and depression thermometers to measure psychosocial morbidity among southern European cancer patients. Support Care Cancer 13(8):600-606

18. Gilbody SM, House AO, Sheldon TA (2001) Routinely administered questionnaires for depression and anxiety: systematic review. Br Med J 322(7283):406-409

19. Goffman E (1963) Stigma: notes on the management of spoiled identity. Penguin, London

20. Goldberg D, Williams P (1988) A user's guide to the General Health Questionnaire. NFER-Nelson, Windsor

21. Hansen HH (2000) Textbook of lung cancer. Dunitz, London

22. Harvey G, Wensing M (2003) Methods for evaluation of small scale quality improvement projects. Qual Safe Health Care 12 (3):210-214

23. Hoffman BM, Zevon MA, D’Arrigo MC, Cecchini TB (2004) Screening for distress in cancer patients: the NCCN RapidScreening Measure. Psycho-Oncology 13(11):792-799

24. Holland J et al (1999) NCCN practice guidelines for the management of psychosocial distress: national comprehensive cancer network proceedings. Oncology 13(Suppl A):113-147

25. Hopwood P, Stephens RJ (2000) Depression in patients with lung cancer: prevalence and risk factors from quality-of-life data. J Clin Oncol 18(4):893-903

26. Hughes R (2005) Is audit research? The relationship between clinical audit and social research. Int J Health Care Quality Assur 18(4):289-299

27. Jacobsen PB, Donovan KA, Trask PC, Fleishman SB, Zabora J, Baker F, Holland JC (2005) Screening for psychological distress in ambulatory cancer patients. A multicenter evaluation of the Distress Thermometer. Cancer 103(7):1494-1502

28. Katona C, Livingston G (2000) Impact of screening old people with physical illness for depression? Lancet 356(9224):91-92

29. Kogan M, Redfern S (1995) Making use of clinical audit. Open University Press, Buckingham

30. Larouche S, Edgar L (2004) The measure of distress: a practical thermometer for outpatient screening. Oncol Exchange 3(3):34-39 
31. Madden J (2006) Use of the Distress Thermometer as a means of effectively assessing emotional distress in patients with cancer. Oncol Nurs Forum 33(2):484-485

32. McDonald MV, Passik SD, Dugan W, Rosenfeld B, Theobald DE, Edgerton S (1999) Nurses recognition of depression in their patients with cancer. Oncol Nurses Forum 26(3):593-599

33. Murphy S (2000) Provision of psychotherapy services for older people. Psychiatric Bulletin 24:184-187

34. National Comprehensive Cancer Network (2005) Clinical Practice Guidelines in Oncology. Distress Management Version 1. [online] Available from: www.nccn.org/professionals/physician-gls/PDF/ distress.pdf (Accessed 16 October 2006)

35. National Institute for Clinical Excellence (2002) Principles for best practice in clinical audit. Radcliffe, Oxon

36. National Institute for Clinical Excellence (2004) Improving supportive and palliative care for adults with cancer: the manual. The Stationary Office, London

37. Ollerton I (1995) Class barriers to psychotherapy and counselling. J Psychiatric Mental Health Nurs 2(2):91-95

38. Passik SD, Dugan W, McDonald MV, Rosenfeld B, Theobald DE, Edgerton S (1998) Oncologists' recognition of depres- sion in their patients with cancer. J Clin Oncol 16(4):15941600

39. Reid-Pointe P (1992) Distress in cancer patient and primary nurses' empathy skills. Cancer Nurs 15:283-293

40. Roth AJ, Kornblith AB, Batel-Copel L, Peabody E, Scher HI, Holland JC (1998) Rapid screening for psychological distress in men with prostate cancer. A pilot study. Cancer 82(10):1904-1908

41. Sapsford R, Jupp V (1996) Data collection and analysis. Sage, London

42. Trask P, Paterson A, Riba M, Brines B, Griffith K, Parker P, Weick J, Steele P, Kyro K, Ferrara J (2002) Assessment of psychological distress in prospective bone marrow transplant patients. Bone Marrow Transplant 29:917-925

43. Vachon M (2006) Psychosocial distress and coping after cancer treatment. Am J Nurs 106(3), (Suppl):26-31

44. Zabora J, Brintzenhofeszoc K, Curbow B, Hooker C, Piantadosi S (2001) The prevalence of psychological distress by cancer site. Psycho-Oncol 10(1):19-28

45. Zabora J, Brintzenhofeszoc K, Jacobsen P, Curbow B, Piantadosi S, Hooker C, Owens A, Derogatis L (2001) A new psychosocial screening instrument for use with cancer patients. Psychosomatics 42(3):241-246 